COMMENT. Chronic use of phenytoin did not result in cognitive deterioration in young adults with well controlled seizures with onset after 16 years of age. Previous reports suggesting PHT-related cognitive deterioration were complicated by poor seizure control and were limited by less sophisticated tests than those used in the above study. Mikati M et al. at the Department of Neurology, Children's Hospital, Harvard Medical School, have found significant differences in potency and plasma concentrations of brand name PHT and generic PHT monotherapy (Epilepsia March/April 1992; $\underline{33}: 359-365$ ). Variability in capsule content may be an important factor to be considered in trials of medications such as PHT that manifest nonlinear pharmacokinetics.

\title{
FAMILIAL PAROXYSMAL ATAXIA: ACETAZOLAMIDE THERAPY
}

A dramatic response to acetazolamide in 3 patients with familial paroxysmal ataxia is reported from the Ipswich Hospital, Neurological Centre, Suffolk, England. Case 1 developed mild squint at 3 years and nystagmus at 6 years. Subsequently she experienced episodes of dysarthria, ataxia and vertigo often accompanied by nausea and vomiting and followed by headache and drowsiness. The attacks lasted from 2 to 24 hours and occurred every 2 weeks. When assessed at 26 years of age the attacks were occurring up to 5 times a week. The EEG was normal and an MRI showed atrophy of the superior cerebellar vermis. Acetazolamide $250 \mathrm{mg}$ bid reduced attacks dramatically over an 8 month observation period. Cases 2 and 3 , sons of Case 1 , developed identical episodes at 1 year and 6 weeks of age, respectively. Both responded to acetazolamide. The father of the index case was ataxic and then chairbound for 13 years and died at age 67. This family was the first described in the U.K. but many may be mislabeled as epilepsy or migraine (Hawkes CH Familial paroxysmal ataxia: report of a family. J Neur Neurosurg and Psych March 1992; 55:212-213.) (Correspondence: Dr. CH Hawkes, Ipswich Hospital, Neurological Centre, Heath Road, Ipswich, Suffolk IP4 5PD, England.)

COMMENT. Provisional diagnoses of basilar migraine and epilepsy had been made initially in 2 of these cases. The accurate diagnosis in 1 individual will often reveal similarly affected family members. Inheritance is autosomal dominant. Acetazolamide is also effective in the treatment of paroxysmal dystonia (tonic seizures) as a presenting manifestation of multiple sclerosis (Sethi KD et al. Neurology April 1992; 42:919-921). Koller W et al. have used acetazolamide successfully in the treatment of essential tremor (Neurology April 1992; 42(Suppl 3):322).

\section{LANDAU-KLEFFNER SYNDROME: LONG-TERM PROGNOSIS}

The long-term follow up of 6 patients and a review of the recent literature on the Landau-Kleffner syndrome ("acquired aphasia with convulsive disorder") are reported from the Department of Neurology, University Hospital Dijkzigt-Rotterdam, the Netherlands. The age at onset was 3-5 $1 / 2$ years, with epilepsy as the first sign in 3 and comprehension deficit in 3 . 